\title{
PREDIKSI BESAR EROSI DENGAN METODE USLE DI KECAMATAN CANDUANG KABUPATEN AGAM
}

\author{
Ahmad Fadhil ${ }^{1}$, Ratna Wilis ${ }^{2}$ \\ Program Studi Geografi \\ Fakultas Ilmu Sosial \\ Email ahmadfadhil285@gmail.com
}

\begin{abstract}
ABSTRAK
Penelitian ini bertujuan untuk membahas tentang Prediksi Besar Erosi di Kecamatan Canduang Kabupaten Agam. Metode yang di pakai metode deskriptif dengan pendekatan kuantitatif. Variabel dalam penelitian ini prediksi erosi yang terjadi pada lahan pertanian yang memiliki tingkat kemiringan lereng yang tinggi dan tutupan lahan yang kecil dengan penentuan atau teknik penanaman yang kurang sesuai dengan konservasi. Penentuan titik sampel dalam penelitian ini dilakukan dengan menggunakan metode sengaja (porposive sampling). Teknik pengumpulan data yang digunakan adalah pengambilan data secara langsung ke lapanga dan data sekunder dari BMKG, BPDAS Agam Kuantan, BNPB, BAPEDA serta pemerintah Kecamatan Canduang. Teknik analisis data yang dilakukan dengan cara observasi dengan teknik analisa data pada peneilitian ini adalah analisa lapangan. Hasil penelitian menemukan : prediksi besar erosi di Kecamatan Canduang terdiri dari ringan, sedang, dan berat, dengan kelas bahaya erosi I, II dan III
\end{abstract}

Kata Kunci : Erosi, USLE, Prediksi

\begin{abstract}
This research aims to discuss Predicion of Erotion in Caduang Subdistrict, Agam Regency. The Method used is descriptive method with quantitaive approach. The variables in this study predict the erotion that occurs on agricultural land cover with the determination or planting technique that is not in accordance with conservation. Determination of sample points in was carried out of using the porposive sampling method. Data collection technique used were primary and secondary data from BMKG, BPDAS-HL Agam Kuantan, BNPB, BAPEDA and Canduang Subdistrict goverment. Data analysis technique carried out by means of observation with data analysis technique in this research are field analysis. The result of research : prediction of erotion in Canduang Subdistrict classed by light, medium and heavy which erosion risk class I, II and III.
\end{abstract}

Keyword : Erotion, USLE, Prediction

\footnotetext{
${ }^{1}$ Mahasiswa Geografi Universitas Negeri padang

${ }^{2}$ Dosen Geografi Universitas Negeri Padang
} 


\section{PENDAHLUAN}

Erosi di seluruh dunia, selama kurang dari 40 tahun terakhir, telah menyebabkan $30 \%$ tanah subur menjadi tidak produktif (Pradhen et al,.2011), dan sekitar 60\% tanah tererosi menutupi aliran sungai dan danau, dan menyebabkan sering terjadinya banjir, serta adanya kontaminasi dari pupuk dan pestisida (Pimentel, 2006). Dalam peritungan dan prediksi erosi, sampai saat ini metode yang masih sering digunakan adalah metode USLE (Universal Soil Loss Equation) yang dikembangkan di National Runoff and Loss Data Center yang didirikan pada tahun 194 oleh The Science Education Administration Amerika Serikat bekerja sama dengan universitas Purdue (Arsyad, 2010).

Penelitian yang akan peneliti lakukan berada di Kecamatan Canduang Kabupaten Agam dengan tujuan penelitian menghiung besar erosi yang terjadi di kecamatan Canduang dengan metode USLE. Erosi adalah suatu proses diamana tanaha dihancurkan (detached) da kemudian dipindahkan ke tempat lain oleh kekkuatan air, angin dan gravitasi (Hardjowigeno, 1995).

Kerusakan yang terjadi akibat adanya erosi adalah kemunduran sifat-sifat kimia dan fisika tanah seperti kehilangan unsur dan bahan organik, meningkatnya kepadatan serta ketahanan penetrasi tanah, dan menurunnya kapaisitas infiltrasi tanah serta kemampuan menahan air.
1.1 Faktor yang Mempengaruhi Erosi

a. Iklim

Terutama di daerah yang beriklim basah, besarnya curah hujan, instensitas, dan distribusi hujan menentukan kekuatan dispersi hujan terhadap tanah, jumlah dan kekuatan aliran permukaan serta setiap tingkat kerusakan erosi yang erjadi. Hal itu tersebut terjadi karena pada setiap kejadian hujan terdapat berbagai ukuran butir hujan. Masingmasing butir memiliki energi kinetik tertentu yang dipengaruhi oleh graavitasi, tahanan udara, dan angin.

b. Topografi

Kemiringan dan panjang lereng adalah dua sifat topografi yang paling berpengaruh terhadap aliran permukaan dan erosi. Selain dari memperbesar jumlah aliran permukaan, semakin curam lereng juga memperbesar energi angkut aliran permukaan. Panjang lereng mempengaruhi aliran air yang mengalir di permukaan tanah. Dengan demikian, lebih banyak air yang mengalir dan semakin besar kecepatannya di bagian bawah lereng dari pada di bagian atas lereng.

c. Vegetasi

Vegetasi merupakan bagian pelindung atau penyangga antara atmosfer dan tanah. Suatu vegetasi penutup tanah yang baik seperti rumput yang teball atau rimba yang lebat akan menghilangkan pengaruh hujan dan topografi terhadap erosi. 
d. Tanah

Berbagai tipe tanah mempnyai kepekaan terhadap erosi yang berbeda-beda. Kepekaan erosi tanah atau mudah tidaknya tanah tererosi adalah fungsi berbagai interaksi sifat-sifat dan kimia tanah. Sifat-sifat fisik dan kimia tanah yang mempengaruhi erosi adalah (1) sifatsifat tanah yang mempengaruhi infiltrasi, permaebilitas, dan kapasitas menahan air terdiri atas tekstur, strukutr, bahan organil, kedalaman, sifat lapisan tanah, sera tingakt kesuburan tanah, dan (2) sifat tanah yang memepengaruhi ketahanan struktur tanah terhadap dispersi dan penghancuran agregat tanah oleh tumbukan butir-butir hujan dan aliran permukaan.

Faktor terjadinya erosi ada beberapa macam salah satunya sifat tanah. Tanah terdiri atas \% debu, $\%$ liat, dan \% pasir. Tanah yang memiliki tingkat kepekaan erosi yang paling tinggi yaitu tanah persentase kandungan debu tinggi, karena debu tidak bisa menyerap air seba debu memiliki tekstur yang halus dan juga licin sehingga tanah yang memiliki kandungan debu jika di lalui oleh air, maka tanah tersebut akan mudah ter-erosi.

e. Manusia

Pada akhirnya manusialah yang menentukan apakah tanah yang diusahakannya akan rusak dan menjadi tidak produktif atau menjadi baik dan produktif secara lestari. Masalah erosi tanah pada umumnya dipandang sebagai maslaah yang berdiri sendiri. Perencanaan umumnya memandang kehilangan lapisan atas tanah hanya sebagai akibat dari proses fisik yang tidak diinginkan. Sebagai akibatnya, mereka mencoba mengatasinya dengan menggunakan metode mekanik seperti teras dan bangunan fisik lainnya. Metode mekanik memang dapat efektif mencegah erosi akan tetapi tidak secara otomatis meningkatkan priduktifitas lahan. Oleh karena itu, pendekatan dan kebijaksanaan baru di perlukan agar konservasi tanah diterima dan tireapkan secara luas dan baiaya layak. Pendekatan baru tersebut di dasarkan kepada peningkatan sistem penggunaan tanah yang mengarah kepada permtumbuhan vegtasi tanah yang lebih baik (Arsyad 2010:149152).

\subsection{Prediksi Erosi}

Metode USLE adalah suatu model erosi yang di rancang ntuk memprediksi erosi rata-rata jangka panjang dari erosi lembar atau erosi alur di bwah keadaan tertentu. Metode ini pertama kali bermanfaat untuk tanah tempat bangunan dan penggunaan no-pertanian, tetapi tidak dapat memprediksi pengendapan dan tidak memperhitungkan hasil sedimen dari erosi parit, tebing sungai, dan dasar sungai. USLE memungkinkan 
perencanaan menduga laju ratarataerosi suatu bidang tanah tertentu di suatu kemiringan lereng dengan pola hujan tertentu untuk setiap macam penanaman dan tindakan pengelolaan yang mungkin di lakukakn atau yang sedang digunakan (Arsyad, 2010:366).

Persamaan USLE (Wischmeier \& Smith, 1978:4) dapat di lihat sebagai berikut :

$\mathrm{A}=\mathrm{R} \times \mathrm{K} \times \mathrm{LS} \times \mathrm{C} \times \mathrm{P}$

Keterangan :

a. Erosivitas Hujan (R), merupakan kemampuan hujan untuk menimbulkan atau menyebabkan erosi. Intesitas hujan yang sangat tinggi juga akan mempengaruhi tingkat erosisivitas.

b. Erodibilitas Tanah (K), merupakan jumlah tanah yang hilang rata-rata setiap tahun per satuan indeks daya erosi curah hujan pada sebidang tanah tanpa tanaman (gundul), tanpa usaha pencegahan erosi, lereng 9\% $\left(5^{\circ}\right)$, dan panjang lereng 22 meter (Hardjowigeno, 199).

c. Indeks Panjang dan Kemiringa Lereng (LS), panjang dan kemiringan lereng mempunyai pengaruh yang besar terhadap perbuhan bentuk muka bumi. Lereng tersebut sangat berhubungan dengan perbedaan ketinggian antar suatu jarak. Lereng yang terjal sering kali lebih banyak terkena hujan dan terpengaruh oleh angin di bandingkan lereng yang datar. d. Indeks Vegetasi Tutupan Lahan dan Pengelolaan Tanaman (C), dimana pengelolaan tanaman penting di lakukan untuk mengurangi dampak erosi. Pengelolaan tanaman yang baik akan menyebabkan tanah lebih mudah menahan air dari pada mengalirkannya secara langsung. Pengelolaan tanaman ini juga berfungsi unuk mengurangi daya utir hujan dalam merusak tanah di bawahnya. Selain itu pengelolaan tanaman ini dapat juga membantu sistem perekatan yang baik di dalam tanah yang di kelola yang kemudian dapat menahan tanah teangkut oleh air. Indeks pengelolaan tanaman ditentukan berdasarkan sifat perlindungan tanaman terhadap erosivitas hujan.

e. Indek Tindakan Khusus Konservasi Tanah (P), faktor praktik konservasi tanah adalah rasio tanah yang hilang bila usaha konservasi tana di lakukan (teras, tanaman dan sebagainya) dengan tanpa adanya usaha konservasi tanah. Tanpa konservasi tanah nilai $\mathrm{P}=1$. Bila diteraskan, nilai $\mathrm{P}$ dianggap sama denga nilai $\mathrm{P}$ untuk strip cropping, sedangkan nilai LS didapat dengan menganggap panjang lereng sebagai jarak horizontal dari masing-masing teras. Konservasi tanah tidak hanya tindakan konservasi secara mekanis dan fisik, tetapi termasuk juga usahausaha yang bertujuan untuk mengurangi erosi tanah. Penilaian faktor $\mathrm{P}$ di lapangan leih muda apabila di gabungkan dengan faktor 
C, karena dalam kenyataannya kedua faktor tersebut berkaitan erat.

\section{METODE PENELITIAN}

Lokasi penelitian terletak di Kecamatan Canduang Kabupaten Agam dengan. Alat dan bahan : Peta tanah, peta kemiringan lereng, peta curah hujan, peta penggunaan lahan yang berguna untuk penentuan kondisi fisik. Data curah hujan tahun 2007-2016, Perangkat komputer atau laptop, serta software pengolahan data seperti Arcgis, Micrsoft Office 2007.

Jenis penelitian menggunakan metode deskriptif dengan pendekatan kuantitatif dengan variael nya prediksi erosi yang terjadi pada lahan pertanian yang memiliki tingkat kemiringan lereng yang tinggi dan tutupan lahan yang kecil denga penentuan atau teknik penanaman yang kurang sesuai dengan konservasi. Penentuan titik sampel dilakukan dengan metode sengaja (porposeive sampling).

Jenis data yang di gunakan adalah data primer yang di peroleh dari pengambilan sampel langsung di lapangan dan data sekunder yang di peroleh dari pustaka dan instansi yang terkait. Teknik pengumpulan data di lakukan dengan teknik pengumpulan data primer dengan cara pengukuran ke lapangan, pengambilan sampel tanah, dan jenis vegetasi yang ada di lapangan, dan teknik pengumpulan data sekunder di peroleh dari buku-buku dan teori- teori yang mendukung peneitian. Teknik analisis data dilakukan dengan cara observasi langsung ke lapangan dan dengan menggunakan rumus USLE itu sendiri.

a. Erosivitas Hujan

Persamaan yang umum digunkan untuk menghitung erosivitas adalah persamaan yang kemukakan oleh (DHV, 1989) sebagai berikut :

IR $=2,21 \mathbf{P}^{1,36}$

Keterangan :

$\mathrm{R}$ : Indeks Erosivitas

P : Curah Hujan (cm)

b.Panjang dan Kemiringan Lereng

Menurut Weismeier dan Smith (1978) dalam Hardjoamijojo dan Sukartaatmadja (1992), faktor lereng dapat ditentukan dengan persamaan :

Faktor $\mathrm{L}=(1 / 22)^{\mathrm{m}}$

Faktor $\mathrm{S}=0.065+0.0454 \mathrm{~s}+0.0065$ $\mathrm{s}^{2}$. (3)

Faktor $\mathrm{S}=(\mathrm{s} / 9) 1.35 \quad$ (untuk $\mathrm{s}>$ $12 \%)$.

$1=1$ kontur pada peta $\mathrm{x}$ skala

$\mathrm{s}=\mathrm{CI} / 1$

$\mathrm{CI}=1 / 2000 \mathrm{x}$ skala

LS = Faktro L $x$ Faktor S.

Keterangan :

$\mathrm{L}$ : Panjang Lereng (m)

$\mathrm{S}:$ Kemiringa Lahan (\%)

$\mathrm{m}$ : Nilai eksponensial yang tergantung dari kemiringan

$$
\begin{aligned}
& \mathrm{S}<1 \% \text { maka } \mathrm{m}=0,2 \\
& \mathrm{~S}=1-3 \% \text { maka } \mathrm{m}=0,3 \\
& \mathrm{~S}=3-5 \% \text { maka } \mathrm{m}=0,4 \\
& \mathrm{~S}>5 \% \text { maka } \mathrm{m}=0,5
\end{aligned}
$$


L : Panjang lereng (m)

S : Kemiringan lahan (\%)

1 kontur : panjang lereng pada kontur

CI : $1 / 2000$ x skala

Nilai LS dapat juga ditentukan menurut kemiringan lerengnya seperti di tujukan pada tabel 1 baerikut :

Tabel 1 : Kemiringan lereng

\begin{tabular}{llll}
\hline $\begin{array}{l}\text { Kelas } \\
\text { Lereng }\end{array}$ & $\begin{array}{l}\text { Kemiringan } \\
\text { Lereng } \mathbf{( \% )}\end{array}$ & Klasifikasi & $\begin{array}{l}\text { Indeks } \\
\text { LS }\end{array}$ \\
\hline I & $0-8$ & Datar & 0,4 \\
\hline II & $8-15$ & Landai & 1,4 \\
\hline III & $15-25$ & $\begin{array}{l}\text { Agak } \\
\text { Curam }\end{array}$ & 3,1 \\
\hline IV & $25-45$ & Curam & 6,8 \\
\hline V & $>45$ & $\begin{array}{l}\text { Sangat } \\
\text { Curam }\end{array}$ & 9,5 \\
\hline
\end{tabular}

Sumber : Modifikasi Indeks Panjang

Kemringan Lereng, Arsyad (2010:440) c. Erodibilitas Tanah

Salah satu cara menghitung erodibilitas tanah adalah Metode Bouyoucos atau disebut juga Metoda clay ratio :

$$
\mathrm{E}=\frac{\% \text { pasir }+\% \text { debu }}{\% \text { lempung }}
$$

d.Indeks Vegetasi Penutup Tanah Dan Pengelolaan Tanaman

Pada tanah ang gundul nilai $\mathrm{C}=1,0$. Untuk mendapatkan nilai $\mathrm{C}$ tahunan perlu diperhatikan perubahanperubahan penggunaan tanah dalam setiap tahun. Besarnya nilai $\mathrm{C}$ pada beberapa kondisi dapat dilitah pada Tabel 2.

Tabel 2 : Nilai faktor $\mathrm{C}$ untuk vegetasi penutup lahan dan pengelolaan tanaman

\begin{tabular}{|c|c|c|c|c|c|}
\hline \multicolumn{6}{|c|}{ Nilai Faktor C untuk Vegetasi penutu lahan dan pengelolaan tanaman } \\
\hline No & Kelas & Nilai & No & Kelas & Nilai \\
\hline 1 & Tanah terbuka/tanpa tanaman & 1,0 & 20 & Hutan produksi : & \\
\hline 2 & Jagung & 0,01 & & -tebang habis & 0,5 \\
\hline 3 & Sawah & 0,7 & & -tebang pilih & 0,2 \\
\hline 4 & Tegalan tidak dispesifikasi & 0,8 & 21 & semak belukar/padang rumput & 0,3 \\
\hline 5 & Ubi kayu & 0,7 & 22 & Ubikayu + kedelai & 0,181 \\
\hline 6 & Kedelai & 0,339 & 23 & ubikayu + kacang tanah & 0,195 \\
\hline 7 & Kentang & 0,4 & 24 & Padi - Sorghum & 0,345 \\
\hline 8 & Kacang tanah & 0,2 & 25 & padi - Keledai & 0,417 \\
\hline 9 & Padi & 0,561 & 26 & Kacang tanah + gude & 0,495 \\
\hline 10 & Tebu & 0,2 & 27 & Kacang tanah + Kacang tunggak & 0,571 \\
\hline 11 & Pisang & 0,6 & 28 & Kacang tanah + Mulsa jerami 4 ton/ha & 0,049 \\
\hline 12 & akar wangi (sereh wangi) & 0,4 & 29 & Padi + Mulsa jerami 4 ton/ha & 0,096 \\
\hline 13 & Rumput bede (tahun pertama) & 0,287 & 30 & Kacang tanah + mulsa jagung 4 ton/ha & 0,128 \\
\hline 14 & Rumput bede (tahun kedua) & 0,002 & 31 & $\begin{array}{l}\text { Kacang tanah + Mulsa crotalaria } 3 \\
\text { ton/ha }\end{array}$ & 0,136 \\
\hline 15 & $\begin{array}{l}\text { Kopi denga penutup tanah } \\
\text { buruk }\end{array}$ & 0,2 & 32 & Kacang tanah + Mulsa Kacang tunggak & 0,259 \\
\hline
\end{tabular}




\begin{tabular}{|c|c|c|c|c|c|}
\hline 16 & Talas & 0,85 & 33 & Kacang tanah + mulsa jerami 2 ton/ha & 0,377 \\
\hline \multirow[t]{2}{*}{17} & Kebun campuran : & & 34 & Padi + mulsa crotalaria 3 ton/ha & 0,387 \\
\hline & $\begin{array}{l}\text {-kerapatan tinggi } \\
\text {-kerapatan sedang } \\
\text {-kerapaatan rendah }\end{array}$ & $\begin{array}{l}0,1 \\
0,2 \\
0,5\end{array}$ & 35 & $\begin{array}{l}\text { Pola tanaman tumpang gilir (jagung } \\
\text { +padi+ubi kayu,setelah panen padi, } \\
\text { ditanam kacang tanah) + mulsa jerami }\end{array}$ & 0,079 \\
\hline 18 & Perladangan & 0,4 & 36 & $\begin{array}{l}\text { pola tanaman berurutan (padi-jagung- } \\
\text { kacang tanah) +mulsa sisa tanaman }\end{array}$ & 0,357 \\
\hline 19 & $\begin{array}{l}\text { Hutan Alam : } \\
\text {-serasah banyak } \\
\text {-serasah kurang }\end{array}$ & $\begin{array}{l}0,001 \\
0,005\end{array}$ & 37 & Alang-alang murni subur & 0,001 \\
\hline
\end{tabular}

Sumber : Data Pusat Penelitian Tanah 1973-1981 (tidak di publikasikan) dalam Arsyad (2010:375)

e.Indeks tindakan khusus konservasi tanah $(\mathrm{P})$

Tanpa konservasi tanah nilai $\mathrm{P}=$ 1. Penilaian faktor P di lapangan leih mudah apaila digabungkan dengan faktor $\mathrm{C}$, karena dalam kenyataan kedua faktor tersebut berkaitan erat. Pemilihan atau peentuan nilai $\mathrm{CP}$ perlu dilakukan dengan hati-hati karena adanya variasi kedaan lahan dan variasi teknik kpnservasi yang dijumpai dilapangan.

Tabel 3 : Nilai Faktor P untuk Teknik Konservasi Tanah

\begin{tabular}{|c|c|c|}
\hline No & Teknik Konservasi Tanah & Nilai P \\
\hline \multirow[t]{4}{*}{1} & Teras bangku & \\
\hline & - Sempurna & 0,04 \\
\hline & - $\quad$ Sedang & 0,15 \\
\hline & - Jelek & 0,35 \\
\hline 2 & Teras tradisional & 0,40 \\
\hline \multirow[t]{3}{*}{3} & Padang rumput (permanent grass field) & \\
\hline & - Bagus & 0,04 \\
\hline & - Jelek & 0,40 \\
\hline 4 & Hill side ditch atau field pits & 0,3 \\
\hline \multirow[t]{4}{*}{5} & Countur cropping & \\
\hline & - Kemiringan $0-8 \%$ & 0,5 \\
\hline & - Kemiringan 9-20\% & 0,75 \\
\hline & - Kemiringan $20 \%$ & 0,9 \\
\hline \multirow[t]{4}{*}{6} & Limbah jerami yang digunakan & \\
\hline & - 6 ton/ha/tahun & 0,3 \\
\hline & - 3 ton/ha/tahun & 0,5 \\
\hline & - 1 ton/ha/tahun & 0,8 \\
\hline \multirow[t]{3}{*}{7} & Tanaman perkebunan & \\
\hline & - Penutupan tanah rapat & 0,1 \\
\hline & - Penutup tanah sedang & 0,5 \\
\hline 8 & Reboisasi dengan penutupan tanah pada awal & 0,3 \\
\hline 9 & $\begin{array}{l}\text { Strip cropping jagung - kacang tanah, sisa } \\
\text { tanaman dijadikan mulsa }\end{array}$ & 0,5 \\
\hline 10 & Jagung - kedelai, sisa tanaman dijadikan & 0,087 \\
\hline
\end{tabular}




\begin{tabular}{lll}
\hline \multicolumn{3}{l}{ mulsa } \\
\hline 11 & Jagung - mulsa jerami padi & 0,008 \\
\hline 12 & Padi gogo - kedelai, mulsa jerami padi & 0,193 \\
\hline 13 & Kacang tanah - kacang hijau & 0,730 \\
\hline
\end{tabular}

Sumber : Abdukrahman, dkk (1981) di dalam Hardjoamidjojo, S. Dan Sukartamadja, S. (1992).

\section{HASIL}

DAN

\section{PEMBAHASAN}

a. Deskripsi Wilayah

Kecamatan Canduang berada di kaki Gunung Marapi berkoordinat $100,30^{\circ} \mathrm{BT}-100,31^{\circ} \mathrm{BT}, 25^{\circ} \mathrm{LS}-$ $0,27^{\circ} \mathrm{LS}$, dengan daerah yang berombak dan berbukit sampai dengan lereng yang sangat terjal. Memiliki luas daerah 53,44 $\mathrm{Km}^{2}$. Kecamatan Canduang berada pada ketinggian antara 780 hingga 2981 $\mathrm{m}$ di atas permukaan laut. Temperatur udara di Kecamatan Canduang adalah antara $20^{\circ} \mathrm{C}$ hingga $28^{\circ} \mathrm{C}$. Kelembaban udara $88 \%$, kecepatan angin antara 4 hingga $20 \mathrm{~km} / \mathrm{jam}$ dan penyinaran matahari rata-rata $58 \%$. Curah hujan daerah kecamatan Canduang adalah antara 3500 hingga 4000 $\mathrm{mm} /$ tahun tanpa bulan kering.

b. Pengambilan Sampel

Pengambilan sampel di lakukan dengan cara membuat peta satuan lahan dengan meng-overlay peta dasar yakni peta tanah, peta penggunaan lahan, peta geologi, peta bentuk lahan dan peta kemiringan lereng.

Dari peta satuan lahan, dilakukan generalisasi peta demi memudahkan dalam perhitungan dan analisa daerah dalam mempridiksi besar laju erosi di
Kecamatan Caduang tersebut. Sehingga yang awalnya terdapat 16 bentuk poligon pada peta, setelah di lakukan generalisasi pada peta, akhirnya menjadi 11 poligon.

Gambar 1 : Peta Satuan lahan

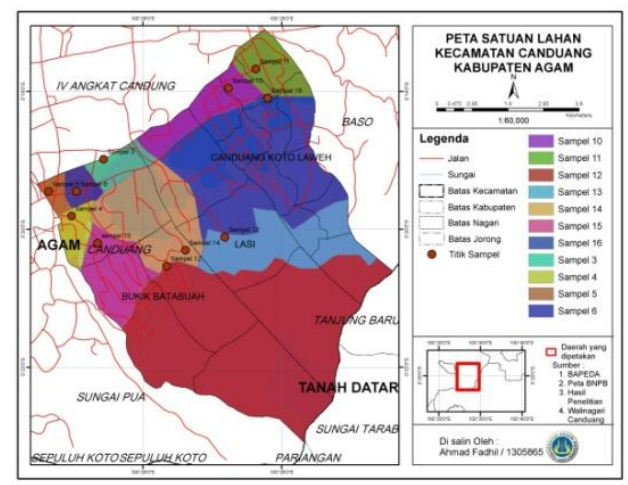

c. Faktor yang mempengaruhi erosi

1) Erosivitas Hujan

Dengan menggunakan rumus IR $=2,21 \mathrm{P}^{1,36}$.

Keterangan :

IR : Indeks erosivitas

P : Curah hujan bulanan

Tabel curah hujan bulanan yang sudah dilakukan analisi dapat dilihat pada tabel 4 dibawah.

Rata - rata curah hujan dalam satuan milimiter bulanan pada tahun 20062016 di masukan ke dalam rumus erosivitas, sehingga di dapat jumlah total erosivitas hujan sebesar 57.560,97. Dari hasil total tersebut di buatkan rata-rata sealama 12 bulan, sehingga didapatkan nilai dari Indeks Erosivitas (IR) yaitu 1476,98.

2) Erodibilitas Tanah 
Generalisasi peta dilakukan untuk luas sampel yang kecil digaungkan ke luas ampel yang berdekatan di karenakan takut terjadi eror dalam penentuan titik yang sudah di lalkukan pengambilan data. Nilai erodibilitas Kecamatan Canduang dapat dilihta pada tabel 5 dibawah. Dari sampel yang di dapatkan nilai $\mathrm{K}$ paling tinggi berada pada sampel 10 yaitu sebesar 0,113 dan nilai $\mathrm{K}$

Tabel 4 : Curah hujan rata-rata tahun 2006-2016 dan indeks erosivitas di Kecamatan Canduang

\begin{tabular}{ccc}
\hline Bulan & $\begin{array}{c}\text { Rata - rata } \\
\text { curah hujan } \\
(\mathbf{m m})\end{array}$ & Erosivitas hujan \\
\hline Januari & 136,854 & 1322,91 \\
\hline Februari & 125,763 & 1185,26 \\
\hline Maret & 157,563 & 1588,86 \\
\hline April & 207,982 & 2279,42 \\
\hline Mei & 99,148 & 870,01 \\
\hline Juni & 111,272 & 1010,88 \\
\hline Juli & 94,509 & 817,54 \\
\hline Agustus & 101,972 & 902,45 \\
\hline September & 137,681 & 1333,31 \\
\hline Oktober & 166,254 & 1703,72 \\
\hline November & 212,554 & 2344,78 \\
\hline Desember & 213,936 & 2364,62 \\
\hline Jumlah & $1.765,487$ & $57.560,97$ \\
\hline \multicolumn{2}{c}{ R rata-rata } & $\mathbf{1 4 7 6 , 9 8}$ \\
\hline
\end{tabular}

Sumber : Hasil Analisis Data

Tabel 5 : Nilai erobilitas tanah (K) Kecamatan Canduang

\begin{tabular}{|c|c|c|c|c|c|c|}
\hline \multirow{2}{*}{ No } & \multirow{2}{*}{ Sampel } & \multicolumn{3}{|c|}{ Tekstur } & \multirow{2}{*}{ Kelas Tekstur } & \multirow[t]{2}{*}{ Nilai $K$} \\
\hline & & $\%$ pasir & $\%$ debu & \% lempung & & \\
\hline 1 & 16 & 38 & 28 & 35 & Lempung Berliat & 0,018 \\
\hline 2 & 10 & 59 & 32 & 8 & Lempung Berpasir & 0,113 \\
\hline 3 & 11 & 68 & 16 & 16 & Lempung Berpasir & 0,052 \\
\hline 4 & 5 & 52 & 25 & 22 & Lempung Liat Berpasir & 0,035 \\
\hline
\end{tabular}




\begin{tabular}{ccccccc}
\hline 5 & 3 & 33 & 32 & 35 & Lempung Berliat & 0,018 \\
\hline 6 & 6 & 37 & 28 & 35 & Lempung Berliat & 0,019 \\
\hline 7 & 12 & 29 & 28 & 43 & Liat & 0,013 \\
\hline 8 & 14 & 33 & 13 & 53 & Liat & 0,008 \\
\hline 9 & 15 & 32 & 39 & 29 & Lempung Berliat & 0,024 \\
\hline 10 & 4 & 45 & 25 & 29 & Lempung Liat Berpasir & 0,025 \\
\hline 11 & 13 & 52 & 31 & 17 & Liat Berpasir & 0,048 \\
\hline \multicolumn{7}{l}{ Sumber : Hasil Analisis Labor Sampel Tanah di Labor Tanah UNAND } \\
\end{tabular}

3) Panjang dan Kemiringan Lereng

Menurut Doni (1995) dari beberapa faktor yang mempengaruhi erosi, kelerengan merupakan faktor yang paling dominan dalam mem-pengaruhi erosi dan walaupun faktor lainnya secara bersama - sama mempengaruhi terjadi-nya erosi, namun tidak begitu kuat secara sendiri-sendiri.

Tabel 6 : Nilai panjang dan kemiringan leren (LS) Kecamatan Canduang

\begin{tabular}{cccc}
\hline No & Sampel & $\begin{array}{c}\text { Kemiringan } \\
\text { Lereng \% }\end{array}$ & $\begin{array}{c}\text { Indeks } \\
\text { LS }\end{array}$ \\
\hline 1 & 16 & 2.5 & 0,73 \\
\hline 2 & 10 & 3.33 & 0,88 \\
\hline 3 & 11 & 2.5 & 0,73 \\
\hline 4 & 5 & 2 & 0,64 \\
\hline 5 & 3 & 3.33 & 0,88 \\
\hline 6 & 6 & 1.67 & 0,6 \\
\hline 7 & 12 & 5 & 1,69 \\
\hline 8 & 14 & 25 & 9,28 \\
\hline 9 & 15 & 5 & 1,69 \\
\hline 10 & 4 & 5 & 1,69 \\
\hline 11 & 13 & 16.67 & 6,75 \\
\hline \multicolumn{5}{r}{ Sumber : Hasil Analisis Data } \\
\end{tabular}

Dari data yang di dapat, nilai LS terbesar terdapat pada sampel 14 dengan nilai indeks sebesar 9,28, sedangkan nilai LS terkecil terdapat pada sampel sampel 6 dengan nilai indeks sebesar 0,6.

4) Tutupan Lahan dan Tindakan Konservasi

Kerakteristik penggunaan lahan terbanyak di Kecamatan Canduang yakni sawah dan ditumpangsarikan dengan tanaman semusim seperti cabe, ubi, kacang tanah, jagung dan lain - lain. Dalam tindak konservasi hanya dilakukan dengan tanaman perkebunan pnutupan tanah rapat sehingga nilai dari CP tidak terlau tinggi yang akan berdampak pada tingkat erosi yang di akibatkan oleh jatuhan air hujan pada lahan tidak terlalu tinggi. 
Tabel 7 : Nilai CP Kecamatan

rapat seperti cabe, ubi, dan lain-lain Canduang

dan nilai penjang dan kemiringan

\begin{tabular}{ccc}
\hline Sampel & C & P \\
\hline \multirow{2}{*}{16} & 0,2 & 0,1 \\
& (Kebun Campran) & (Tanaman Perkebunan) \\
\hline & 0,079 &
\end{tabular}
CP pada daerah tersebut cukup tingsisehingga setelah dimasukan ke

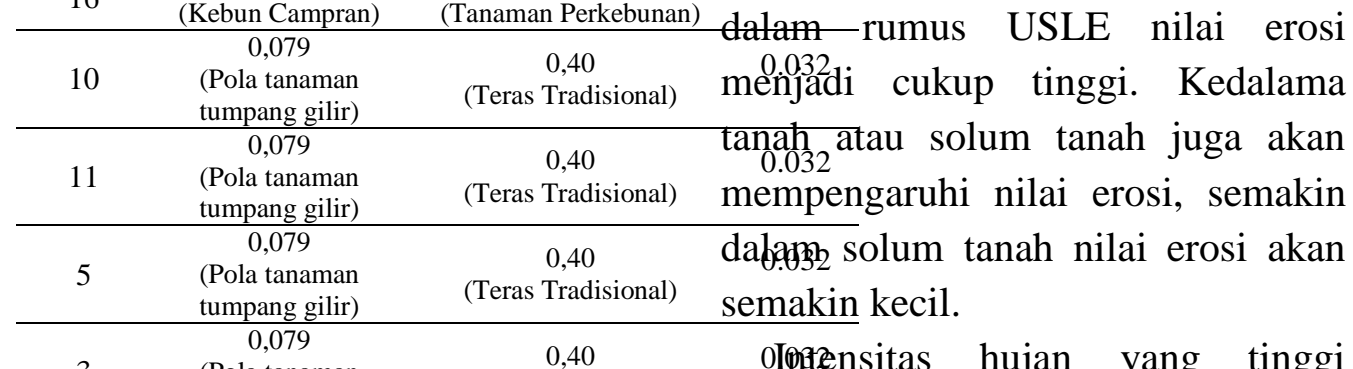

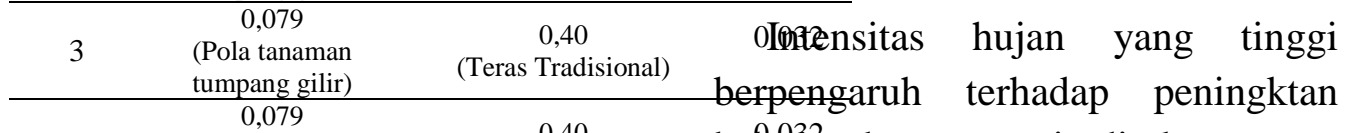

\begin{tabular}{|c|c|c|c|}
\hline 6 & $\begin{array}{c}0,079 \\
\text { (Pola tanaman } \\
\text { tumpang gilir) }\end{array}$ & $\begin{array}{c}0,40 \\
\text { (Teras Tradisional) }\end{array}$ & ar erosi \\
\hline
\end{tabular}

\begin{tabular}{cccc}
\hline 0,2 & 0,1 & Cabgdtrang. Dari perspektif lokal, \\
12 & (Tebu) & (Tanaman Perkebunan) & sebuah studi tentang tren curah hujan \\
\hline 0,005 & 0,1 & 0.0005
\end{tabular}
$14 \quad \begin{gathered}0,005 \\ \text { (Hutan alam) }\end{gathered}$ (Tanpa tindak konservasi) ekstrem di Padang untuk periode

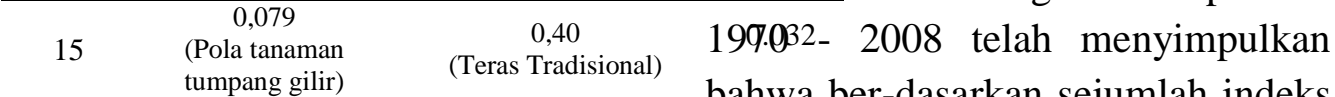

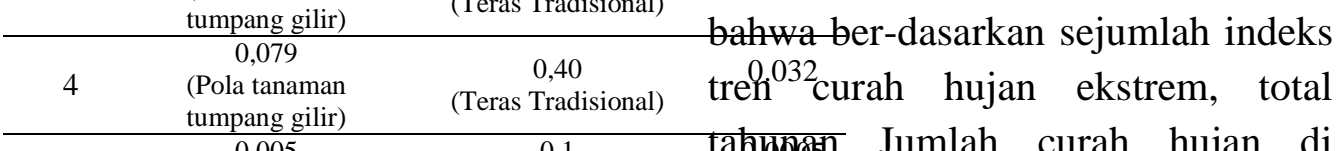

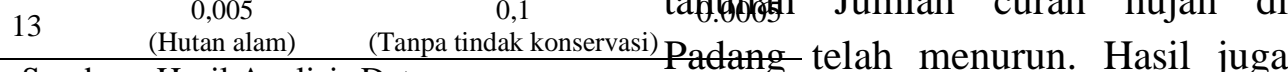
Sumber : Hasil Analisis Data

Dari informasi yang di tampilkan pada peta kelas bahaya erosi yang sudah di overlay dengan administrasi jorong di kecamatan Canduang, kelas bahaya erosi dengan kelas sedang terdapat pada jorong Kubang Duo Koto Panjang, Batabuah Koto Baru, Lasi Mudo, III Suku, III Kampuang, 100 Janjang, Lubuak Aua, Bingkudu, Batu Balantai dan sedikit di jorong Gobah.

Kelas bahaya erosi dengan kelas sedang pada sepuluh jorong tersebut diakibatkan oleh pengelolaan tanaman konnservasi yang tidak cukup baik karena di daerah tersebut bisa di lihat pada peta satuan lahan sebagai pertaian lahan kering yang memiliki tutupan lahan yang tidak menunjukkan bahwa jumlah curah hujan di Padang diakumulasikan dalam waktu tertentu dalam periode pengamatan, yang mengarah ke kecenderungan peningkatan intensitas curah hujan di kota. (S. Nugroho dan Raatna Williss, IOP Conf. Seri : 2018).

Tingkat bahaya erosi menjadi berat pada ketiga jorong tersebut juga di akibatkan solum tanah yang cukup dangkal sehingga pada nilai besar erosi yang di hitung mengguanakan rumus USLE tersebut jika di masukan dalam penentuan kelas tingkat bahaya erosi yang di kaitkan dengan solum atau kedalaman tanah jika solum tanah 
nya dangkal akan berakibat kelas tingkat bahaya erosi menjadi berat.

Kelas tingkat bahaya erosi dengan kelas ringan lebih banyak terdapat pada kecamatan Canduang, karena nilai erodibilitas tanah, nilai panjang dan kemiringan lereng, pengelolaan dan konservasi tanaman yan cukup merata pada daera tersebut, dan juga solum yang tidak terlalu dalam membuat nilai kelas menjadi sedang. Pada kelas yang ringan yang terdapat pada jorong Kubang Duo Koto Panjang, Gobah, Batabuah Koto Baru, Batang Salisiah, Lasi Tuo, Pasanehan, Labuang, XII Kampuang, Canduang Tabel 8 : Besar Erosi di Kecamatan Canduang

\begin{tabular}{|c|c|c|c|c|c|c|c|c|}
\hline Sampel & $\mathbf{R}$ & $\mathbf{K}$ & $\mathbf{L S}$ & $\mathbf{C P}$ & A & $\begin{array}{c}\text { Kelas } \\
\text { Bahaya } \\
\text { Erosi }\end{array}$ & $\begin{array}{l}\text { Kedalaman } \\
(\mathbf{c m})\end{array}$ & $\begin{array}{c}\text { Kelas } \\
\text { Tingkat } \\
\text { Bahaya } \\
\text { Erosi } \\
\end{array}$ \\
\hline 16 & 87,31 & 0,018 & 0,73 & 0,02 & 0,406 & I & 56 & S II \\
\hline 10 & 87,31 & 0,113 & 0,88 & 0,032 & 4,671 & I & 61 & R I \\
\hline 11 & 87,31 & 0,052 & 0,73 & 0,032 & 1,788 & I & 62 & R I \\
\hline 5 & 87,31 & 0,035 & 0,64 & 0,032 & 1,045 & I & 56 & S II \\
\hline 3 & 87,31 & 0,018 & 0,88 & 0,032 & 0,762 & I & 51 & S II \\
\hline 6 & 87,31 & 0,019 & 0,6 & 0,032 & 0,521 & I & 58 & S II \\
\hline 12 & 87,31 & 0,013 & 1,69 & 0,02 & 0,661 & I & 68 & R I \\
\hline 14 & 87,31 & 0,008 & 9,28 & 0,0005 & 0,059 & I & 67 & R I \\
\hline 15 & 87,31 & 0,024 & 1,69 & 0,032 & 1,931 & I & 49 & S II \\
\hline 4 & 87,31 & 0,025 & 1,69 & 0,032 & 1,903 & I & 47 & S II \\
\hline 13 & 87,31 & 0,048 & 6,75 & 0,0005 & 0,243 & I & 68 & R I \\
\hline
\end{tabular}

Sumber : Hasil Penelitian
Guguak Ketek, Bingkudu, Batu Balantai, dan Gantiang Koto Tuo, pengelolaan tanaman yang di lakukan pada daerah tersebut baik karena di lakukan pola tanam tumpang gilir sehingga nilai pada $\mathrm{C}$ menjadi rendah, serta pada jorong Lasi Tuo, Bingkudu, Batu Balantai dan Gantiang Koto Tuo, pengguanaan di daerah tersebut masih dalam bentuk kawasan hutan sehingga pada nilai CP sangat rendah yang mengakibat-kan nilai erosi pada daerah tersebut menjadi rendah. 


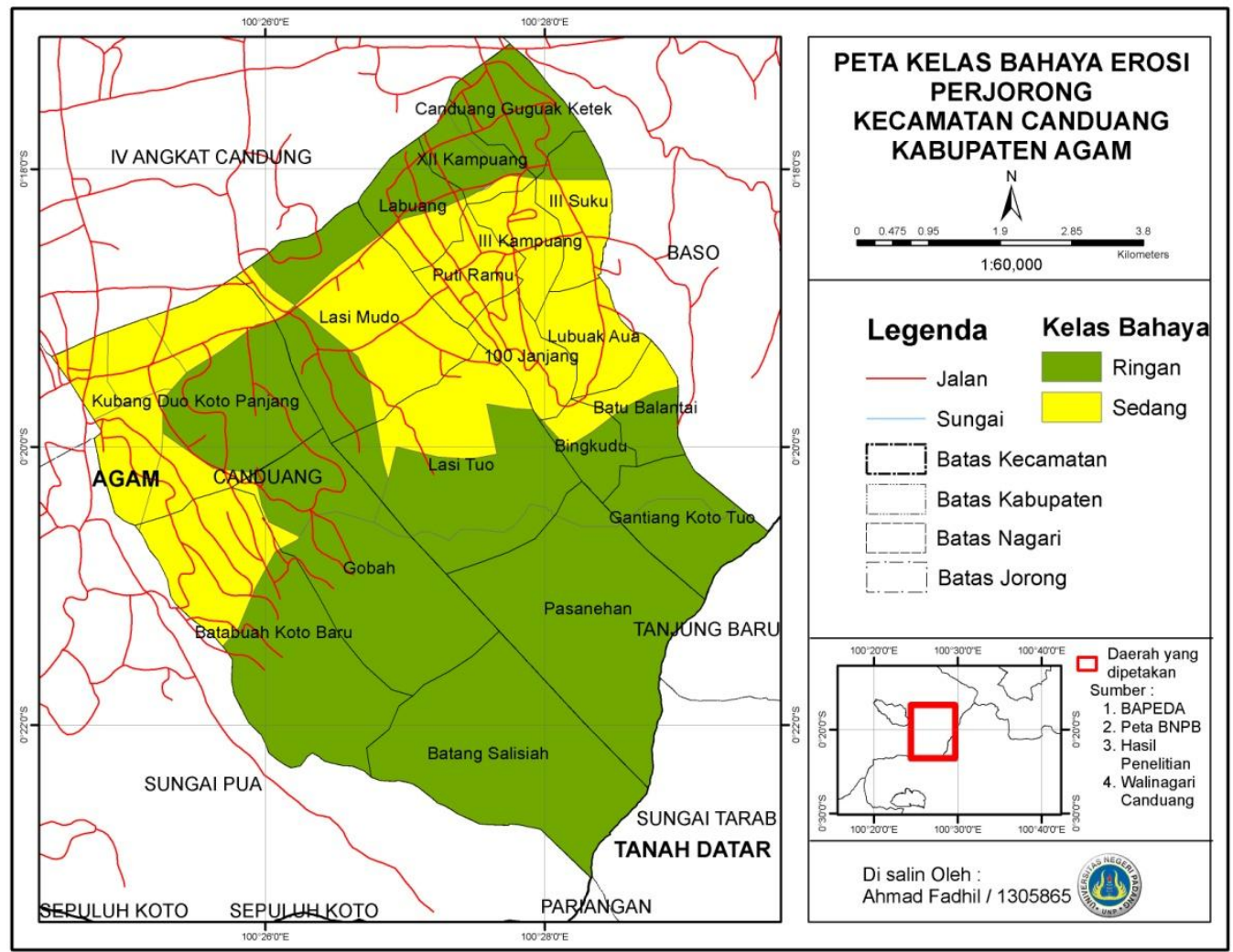

Gambar 2 : Peta Bahaya Erosi

\section{KESIMPULAN}

Dari hasil penelitian prediksi besar erosi yang di lakukan di Kecamatan Canduang, dapat di simpulkan bahwa prediksi besar erosi di Kecamatan Canduang terdiri dari ringan (R II) dan kelas tingkat bahaya erosi sedang (S I). Daerah yang memiliki nilai erosi ringan terdapat pada jorong Kubang Duo Koto Panjang, Gobah, Batabuah Koto Baru, Batang Salisiah, Lasi Tuo, Pasanehan, Labuang, XII Kampuang, Canduang Guguak Ketek, Bingkudu, Batu Balantai, dan Gantiang Koto Tuo. Daerah yang memiliki nilai erosi sedang terdapat pada jorong Kubang Duo Koto Panjang, Batabuah Koto Baru, Lasi Mudo, III Suku, III Kampuang, 100 Janjang, Lubuak Aua, Bingkudu, Batu Balantai dan sedikit di jorong Gobah.

\section{DAFTAR PUSTAKAN}

A'yunin, Qurratul. 2008. Prediksi Tingkat Bahaya Erosi Metode USLE Di Lereng Timur Gunung Sindoro. Skripsi. Universitas Sebelas Maret.

Arikunto, Suharsimi. 2010. Prosedur Penelitian. Jakarta: Rineka Cipta.

Arsyad, S. 2000. Konservasi Tanah dan Air. IPB Press. Bogor. 
Arzi, Zulfikri. 2012. Prediksi Erosi Menggunakan Metode USLE Di Gunung Sanggabuana Jawa Barat. Skripsi. Universitas Indonesia.

Badan Pusat Statistik Kabupaten Agam. 2011-2016. Agam Dalam Angka.Kabupaten Agam. Demi Percetakan, CV.

Banua, IS. 2013. Erosi. PRENAMEDIA GROUP. Jakarta.

Haerdjowigeno, S. 1995. Ilmu Tanah. Akademika Presindo. Jakarta.

Hardiyatmo, HC. 2012. Tanah Longsor dan Erosi.Gadjah University Press. Yogyakarta.

Nugroho, S dan Ratna Willis. 2018. The Decreasing Trend of Praticipation Observed at Watersheds in Indonesia. IOP Converence Series : Earth and Enviromental Science.

Pimentel, D. 2006. Soil Erosion : Food and Environmental Threat. Journal of Environment,Development and Sustanability.

Pradhan. B, A. Chaudhari, J. Adinarayana,F. Manfred., and Buchroithner. 2011.Soil Erosion Assessment and its Correlation with Landslide Events using Remote Sensing Data and GIS: A Case Study at Penang Island, Malaysia.Environmental Monitoring and Assessment

Purnama, Nurina Endra. 2008.Pendugaan Erosi Dengan
Metode USLE (Universal Soil Loss Equation)Di Situ Bojongsari, Depok. Skripsi. Institut Pertanian Bogor.

Risse, L.M., M.A. Nearing, A.D. Nicks, and J.M. Laen. 1993. Error Assessment in the Universal Soil Loss Equation. Soil. Sci. Soc. Am. J. Vol. 57 : 825-833.

Sugiyono. 2014. Metode Penelitian Administrasi. Bandung: ALFABETA

Sutrisna. N， S.R.P.Sitorus. , K. Subagyono.2010. Tingkat Kerusakan Tanah di Hulu Sub DAS Cikapundung Kawasan Bandung Utara. Jurnal Tanah dan IklimNo. 32

Wischmeier,W.H., and D.D. Smith. 1978. Predicting Rainfall Erosion Losses : A Guide to Conservation Planning. USDAAgric, Handb. No. 537 